\title{
Pulmonary artery ablation to treat pulmonary arterial hypertension: a case report
}

Márcio Galindo Kiuchi 1,2,3*, Bruno Rustum Andrea ${ }^{3}$, Gustavo Ramalho da Silva ${ }^{1,2}$, Sandro Barros Pinto Coelho ${ }^{4}$, Luis Marcelo Rodrigues Paz ${ }^{4}$, Shaojie Chen ${ }^{5,6}$ and Gladyston Luiz Lima Souto ${ }^{1,2}$

\begin{abstract}
Introduction: Idiopathic pulmonary arterial hypertension is defined as a group of diseases characterized by a progressive increase in pulmonary vascular resistance that results in right heart failure and premature death. Although therapies exist to improve hemodynamic instability and symptoms, there is no cure for pulmonary arterial hypertension and it remains a life-threatening condition. A recent study performed in China reported, for the first time, the effect of pulmonary arterial denervation on functional capacity and hemodynamics in patients with refractory idiopathic pulmonary arterial hypertension.
\end{abstract}

Case presentation: We report a case of a 60-year-old white Brazilian man, with controlled hypertension and stage 2 obesity who complained of progressive fatigue with moderate to light exertion of approximately 1 year's duration. During this period, he underwent myocardial perfusion scintigraphy without evidence of obstructive ischemic disease. He had no clinical evidence of systolic heart failure. He had undergone biological mitral valve replacement 3 years previously for mitral valve stenosis and ablation of atrioventricular nodal reentry tachycardia 18 months previously. At the time of valve replacement, he had no reported evidence of pulmonary arterial hypertension. His echocardiogram showed normal function of a mitral prosthesis, normal global left ventricular systolic function (left ventricular ejection fraction $62 \%$ measured using the Teichholz method), stage I diastolic dysfunction, and a mean systolic pulmonary arterial blood pressure of $50 \mathrm{mmHg}$. In the 6-minute walk test, the patient walked 104 meters. Catheterization of his right heart chambers and pulmonary arteries confirmed the diagnosis of pulmonary hypertension. Electroanatomic reconstruction of the right ventricular outflow tract and pulmonary artery was performed under direct fluoroscopic visualization, and a merger was made with a formatted image of cardiac computed tomography angiography. Then we performed irrigated cardiac catheter ablation of the pulmonary trunk.

Conclusions: At the patient's 3-month follow-up, he showed improvement in functional class for fatigue on major exertion, increased distance walked in the 6-minute walk test, and reductions in pressure of both the right cavities and the pulmonary artery. Currently, with 6 months of clinical follow-up, the patient has maintained his functional classification and is pedaling his bicycle.

Keywords: Pulmonary arterial hypertension, Catheter ablation, Denervation, 6-Minute walk test, Pulmonary arterial pressure

\footnotetext{
* Correspondence: marciokiuchi@gmail.com

${ }^{1}$ Department of Cardiac Surgery and Artificial Cardiac Stimulation, Sao

Goncalo Hospital and Clinic, São Gonçalo, RJ, Brazil

${ }^{2}$ Department of Medicine, Sao Goncalo Hospital and Clinic, São Gonçalo, RJ, Brazil

Full list of author information is available at the end of the article
}

\section{Biomed Central}

(c) 2015 Kiuchi et al. Open Access This article is distributed under the terms of the Creative Commons Attribution 4.0 International License (http://creativecommons.org/licenses/by/4.0/), which permits unrestricted use, distribution, and reproduction in any medium, provided you give appropriate credit to the original author(s) and the source, provide a link to the Creative Commons license, and indicate if changes were made. The Creative Commons Public Domain Dedication waiver (http://creativecommons.org/publicdomain/zero/1.0/) applies to the data made available in this article, unless otherwise stated. 


\section{Introduction}

Idiopathic pulmonary arterial hypertension is defined as a group of diseases characterized by a progressive increase in pulmonary vascular resistance that results in right heart failure and premature death [1-7]. Recent therapeutic advances have improved the treatment options, including prostanoids, endothelin receptor antagonists, and phosphodiesterase type 5 inhibitors [3-6, 8, 9]. The pathogenesis of idiopathic pulmonary arterial hypertension is believed to be due to an imbalance between locally produced vasodilators and vasoconstrictors [10]. Recent studies have demonstrated that vascular wall remodeling also contributes to elevated pulmonary vascular resistance [11]. A meta-analysis of 23 randomized controlled trials demonstrated a reduction in mortality of patients who used targeted therapies approved for use in patients with pulmonary arterial hypertension [10].

\section{Case presentation}

A 60-year-old white Brazilian man, with controlled hypertension and stage 2 obesity presented to our institution with a complaint of progressive fatigue with moderate to light exertion of approximately 1 year's duration. During that period, he had undergone myocardial perfusion scintigraphy without evidence of obstructive ischemic disease. $\mathrm{He}$ had no clinical evidence of systolic heart failure. He had undergone biological mitral valve replacement 3 years previously for mitral valve stenosis and had undergone ablation of atrioventricular nodal reentry tachycardia 18 months previously. At the time of valve replacement, there was no reported evidence of pulmonary arterial hypertension. The patient's medication list included aspirin $100 \mathrm{mg} /$ day, carvedilol $50 \mathrm{mg} /$ day, atorvastatin 10 $\mathrm{mg} /$ day, and losartan $25 \mathrm{mg} /$ day. His echocardiogram showed normal function of a mitral prosthesis, global left ventricular systolic function within normal limits (left ventricular ejection fraction $62 \%$ measured using the Teichholz method), stage I diastolic dysfunction, and mean pulmonary arterial systolic blood pressure of 50 mmHg. In the 6-minute walk test, the patient walked 104 meters (Table 1). Catheterization of his right heart chambers and pulmonary arteries confirmed the diagnosis of pulmonary hypertension (Table 2). During the follow-up period, therapy with nifedipine and sildenafil was not tolerated secondary to orthostatic hypotension. The patient was referred for radiofrequency ablation of the pulmonary

Table 1 6-Minute walk test results

\begin{tabular}{ll}
\hline Time point & Distance \\
\hline Baseline & $104 \mathrm{~m}$ \\
3 months after ablation & $250 \mathrm{~m}$ \\
6 months after ablation & $302 \mathrm{~m}$ \\
\hline
\end{tabular}

Table 2 Right catheterization and mean systolic blood pressure measurements before and after pulmonary artery ablation

\begin{tabular}{llll}
\hline Structures & Baseline & 3 months & 6 months \\
\hline Right pulmonary arterial pressure, $\mathrm{mmHg}$ & 46 & 35 & 31 \\
Left pulmonary arterial pressure, $\mathrm{mmHg}$ & 46 & 33 & 30 \\
Pulmonary artery trunk pressure, $\mathrm{mmHg}$ & 47 & 36 & 29 \\
Right ventricular pressure, $\mathrm{mmHg}$ & 40 & 33 & 30 \\
Right atrial pressure, $\mathrm{mmHg}$ & 20 & 14 & 11 \\
\hline
\end{tabular}

artery trunk for the treatment of refractory pulmonary hypertension.

The procedure was performed in the catheterization laboratory with direct visualization using fluoroscopy and radiopaque contrast dye. The patient remained under unconscious sedation. Catheterization of the right femoral artery via the standard Seldinger technique was performed using an 8-French valved short sheath after subcutaneous injection of a local anesthetic. Subsequently, this sheath was replaced with a steerable long sheath (Agilis ${ }^{\oplus}$; St. Jude Medical, St. Paul, MN, USA) using the standard over-thewire technique. Unfractionated heparin was administered intravenously, targeting an activated coagulation time between 250 and 350 seconds. Electroanatomic reconstruction of both the right ventricular outflow tract and pulmonary artery was performed using the EnSite Velocity Cardiac Mapping System (St. Jude Medical) under direct fluoroscopic visualization, and a merger was made with the formatted image obtained by performing cardiac computed tomography angiography (Fig. 1). The Agilis ${ }^{\oplus}$ sheath was advanced into the right ventricular outflow tract just before reaching the pulmonary valve. Through this long sheath, we introduced an ablation catheter with an open irrigated tip (St. Jude Medical). The parameters used for each application according to our protocol were as follows: power of $5 \mathrm{~W}$, maximum temperature of $48{ }^{\circ} \mathrm{C}$, 60-second duration in each spot, maximum impedance variation of $10 \%$ from baseline values, and an irrigation flow rate of $17 \mathrm{ml} /$ minute, which created a circle in the pulmonary artery trunk.

The patient was discharged the next morning. No noteworthy changes before or after the procedure or before discharge in the patient's radiographic or echocardiographic laboratory parameters were seen. The patient's blood pressure in both the right heart chambers and the pulmonary artery were determined using catheterization before and at 3 and 6 months after the procedure. The results are shown in Table 2. At the patient's 3-month follow-up examination, he showed an improvement in functional class for fatigue with major exertion. He also demonstrated an increased distance walked in the 6-minute walk test and reduction of the pressures in both the right cavities and the pulmonary artery. Currently, with 6 months of clinical follow-up, he 


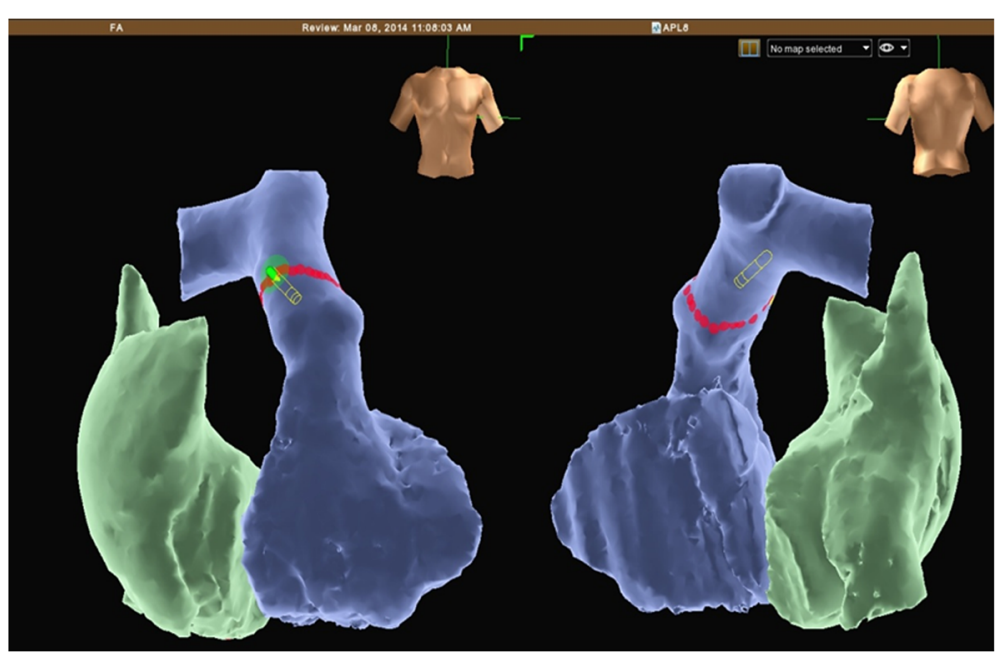

Fig. 1 Electroanatomic reconstruction of the right ventricular outflow tract and pulmonary artery was performed using the EnSite Velocity Cardiac Mapping System, and a merger was made with a formatted image obtained by performing cardiac computed tomography angiography

has maintained his improvement in functional classification and is pedaling his bicycle.

\section{Discussion}

There is no cure for pulmonary arterial hypertension, and it remains a life-threatening disorder, though therapies can improve patients' symptoms, hemodynamics, and outcomes [12]. A recent study performed in China reported, for the first time, the effect of pulmonary arterial denervation on functional capacity and hemodynamics in patients with refractory idiopathic pulmonary arterial hypertension [13].

\section{Conclusion}

The ablation of the pulmonary artery could be a promising tool in the future for the treatment of pulmonary hypertension.

\section{Consent}

Written informed consent was obtained from the patient for publication of this case report and any accompanying images. A copy of the written consent is available for review by the Editor-in-Chief of this journal. The ethics committee (Paola Baars Gomes Moises, Luis Marcelo Rodrigues Paz, Humberto Cesar Tinoco, and Jonny Shogo Takahashi) at our institution approved the execution of the case.

\section{Competing interests}

The authors declare that they have no competing interests.

\section{Acknowledgments}

We thank Sérgio Oliveira and Pacemed for their technical support.

\section{Author details}

'Department of Cardiac Surgery and Artificial Cardiac Stimulation, Sao Goncalo Hospital and Clinic, São Gonçalo, RJ, Brazil. '2Department of Medicine, Sao Goncalo Hospital and Clinic, São Gonçalo, RJ, Brazil. ${ }^{3}$ Electrophysiology Division, Department of Cardiology, Sao Goncalo Hospital and Clinic, São Gonçalo, RJ, Brazil. ${ }^{4}$ Interventional Cardiology Section, Department of Cardiology, Sao Goncalo Hospital and Clinic, São Gonçalo, RJ, Brazil. ${ }^{5}$ Department of Cardiology, Shanghai First People's Hospital, Shanghai Jiao Tong University School of Medicine, Shanghai, China. ${ }^{6}$ Department of Cardiology, Elisabethinen University Teaching Hospital Linz, Linz, Austria.

Received: 19 October 2015 Accepted: 11 November 2015 Published online: 16 December 2015

\section{References}

1. Galiè N, Hinderliter AL, Torbicki A, Fourme T, Simonneau G, Pulido T, et al. Effects of the oral endothelin-receptor antagonist bosentan on echocardiographic and Doppler measures in patients with pulmonary arterial hypertension. J Am Coll Cardiol. 2003;41:1380-6.

2. Galiè N, Seeger W, Naeije R, Simonneau G, Rubin $\sqcup$. Comparative analysis of clinical trials and evidence-based treatment algorithm in pulmonary arterial hypertension. J Am Coll Cardiol. 2004;43:81S-8S.

3. Humbert M, Sitbon $\mathrm{O}$, Simonneau G. Treatment of pulmonary arterial hypertension. N Engl J Med. 2004;351:1425-36.

4. Galiè N, Humbert M, Vachiery JL, Vizza CD, Kneussl M, Manes A, et al. Effects of beraprost sodium, an oral prostacyclin analogue, in patients with pulmonary arterial hypertension: a randomized, double-blind, placebo-controlled trial. J Am Coll Cardiol. 2002;39:1496-502.

5. Farber HW, Loscalzo J. Pulmonary arterial hypertension. N Engl J Med. 2004; 351:1655-65.

6. Galiè N, Olschewski H, Oudiz RJ, Torres F, Frost A, Ghofrani HA, et al. Ambrisentan for the treatment of pulmonary arterial hypertension: results of the ambrisentan in pulmonary arterial hypertension, randomized, double-blind, placebo-controlled, multicenter, efficacy (ARIES) study 1 and 2. Circulation. 2008;117:3010-9.

7. Humbert M, Sitbon O, Chaouat A, Bertocchi M, Habib G, Gressin V, et al. Survival in patients with idiopathic, familial, and anorexigen-associated pulmonary arterial hypertension in the modern management era. Circulation. 2010;122:156-63.

8. Barst R, Ivy DD, Gaitan G, Szatmari A, Rudzinski A, Garcia AE, et al. A randomized, double-blind, placebo-controlled, dose-ranging study of oral sildenafil citrate in 
treatment-naive children with pulmonary arterial hypertension. Circulation. 2012;125:324-34

9. Oudiz RJ, Brundage BH, Galiè N, Ghofrani HA, Simonneau G, Botros FT, et al. Tadalafil for the treatment of pulmonary arterial hypertension: a double-blind 52-week uncontrolled extension study. J Am Coll Cardiol. 2012;60:768-74.

10. Galiè N, Manes A, Negro L, Palazzini M, Bacchi-Reggiani ML, Branzi A. A meta-analysis of randomized controlled trials in pulmonary arterial hypertension. Eur Heart J. 2009;30:394-403.

11. Hoeper MM, Barberia JA, Channick RN, Hassoun PM, Lang IM, Manes A, et al. Diagnosis, assessment, and treatment of non-pulmonary arterial hypertension pulmonary hypertension. J Am Coll Cardiol. 2009;54:585-96.

12. Rich $\mathrm{S}$. The value of approved therapies for pulmonary arterial hypertension. Am Heart J. 2007;153:889-90.

13. Chen SL, Zhang FF, Xu J, Xie DJ, Zhou L, Nguyen T, et al. Pulmonary artery denervation to treat pulmonary arterial hypertension: the single-center, prospective, first-in-man PADN-1 Study (First-in-Man Pulmonary Artery Denervation for Treatment of Pulmonary Artery Hypertension). J Am Coll Cardiol. 2013;62:1092-100.

\section{Submit your next manuscript to BioMed Central and take full advantage of:}

- Convenient online submission

- Thorough peer review

- No space constraints or color figure charges

- Immediate publication on acceptance

- Inclusion in PubMed, CAS, Scopus and Google Scholar

- Research which is freely available for redistribution 